

\title{
Introdução
}

\section{Viajantes em busca da alteridade e da compreensão das dinâmicas de criação da vida e do conhecimento}

\author{
Carlos Eduardo Ferraço \\ Maria da Conceição Silva Soares \\ Nilda Alves
}

\section{SciELO Books / SciELO Livros / SciELO Libros}

FERRAÇO, C.E., SOARES, M.C.S., AND ALVES, N. Introdução - Viajantes em busca da alteridade e da compreensão das dinâmicas de criação da vida e do conhecimento. In: Michel de Certeau e as pesquisas nos/dos/com os cotidianos em educação [online]. Rio de Janeiro: EdUERJ, 2018, pp. 9-17. ISBN 978-85-7511-517-6. https://doi.org/10.7476/9788575115176.0001.



All the contents of this work, except where otherwise noted, is licensed under a Creative Commons Attribution 4.0 International license.

Todo o conteúdo deste trabalho, exceto quando houver ressalva, é publicado sob a licença Creative Commons Atribição $\underline{4.0}$.

Todo el contenido de esta obra, excepto donde se indique lo contrario, está bajo licencia de la licencia $\underline{\text { Creative Commons }}$ $\underline{\text { Reconocimento } 4.0 .}$. 


\section{INTRODUÇÃO}

\section{Viajantes em busca da alteridade e da compreensão das dinâmicas de criação da vida e do conhecimento}

Neste livro nos propomos a apresentar e conversar com algumas ideias do pensador francês Michel de Certeau (1925-86), nosso velho conhecido. Veremos como as "usamos", da maneira que ele propôs, para, em diálogo com outros pensadores e com os praticantespensantes (Oliveira, 2012) da cultura, pensar o que se cria no dia a dia da vida nas/com as escolas e nas/com as múltiplas redes educativas. Redes nas quais vivemos, formamos e nos formamos, pesquisamos e aprendemosensinamos, na tendência em pesquisa que há mais de vinte anos vem se constituindo e consolidando como Pesquisas nos/ dos/com os cotidianos em Educação.

Quanto mais lemos Certeau, mais nos damos conta da atualidade de suas ideias. Também notamos a potência de sua proposta/aposta teórico-metodológico-epistemológico-política para pensar a contemporaneidade e os modos possíveis para nos movimentarmos no mundo, diferindo e tecendo outras/ novas possibilidades para a produção de conhecimentos e para uma vida afirmativa no encontro com o Outro, com a alteridade, informados por interesses e desejos de seus praticantespensantes para muito além, e apesar do que é imposto pelos mercados e pelas políticas de Estado, quiçá pelas políticas que nos são enfiadas goela abaixo pelos administradores do mundo neoliberal e globalizado.

Nós, os cotidianistas - como são conhecidos os pesquisadores que se reconhecem nessa tendência em pesquisa - , te- 
mos, durante todo esse tempo, produzido diálogos com/entre Certeau e com/entre diferentes autores, conforme as demandas dos cotidianos aos quais nos dedicamos. São nomes como Bruno Latour, Homi Bhabha, Boaventura de Sousa Santos, Michel Foucault, Gilles Deleueze, Félix Guattari, Edgar Morin e Judith Buttler, entre outros. Nossos interesses em pesquisa também são variados, abarcando diferentes temáticas que atravessam a Educação, como currículo, avaliação, formação de professores, práticas docentesdiscentes, usos das mídias e tecnologias da comunicação e informação, aprendizagens com as artes e com os espaçostempos das cidades, a diáspora dos afrodescendentes, a intolerância religiosa, o racismo e as disputas em torno das questões de gênero e sexualidade, entre outros.

Em comum, temos a aposta nos cotidianos como espaçostempos de criação de conhecimentos e de produção da vida social, além de uma atitude em pesquisa implicada com os praticantespensantes das escolas e das redes educativas e com os saberesfazeres que eles tecem nas redes, que por sua vez compõem uma trama de conhecimentos e artes de fazer nos diferentes contextos em que vivem, criando sempre diferenças com o desvio produzido pelas práticas. Essa atitude - de insubmissão e invenção de outras possibilidades diante do que nos oprime - que restringe e/ou constrange encontramos no modo como percebemos e interpretamos a trajetória de vida do próprio Certeau.

Michel de Certeau - historiador-vagabundo e jesuíta-errante, conforme definição astuciosa de Diana Gonçalves Vidal (2005) - foi um intelectual atento às práticas, às crenças e às invenções cotidianas que forjaram as redes de saberesfazeres, as relações de poder, as transformações culturais, as crises institucionais e as tensões sociais que agitaram e conformaram os espaçostempos em que trabalhou, estudou, militou, escreveu, visitou 
e viveu com outros. Sacerdote, professor e pesquisador, Certeau transitou por múltiplos caminhos já percorridos pelo pensamento e pelos pensadores, abriu trilhas para explorar novas sensibilidades e atravessou fronteiras entre campos do conhecimento, lugares e épocas; produzindo, permanentemente, diferença com sua trajetória acadêmica, religiosa, política e existencial.

Certeau aonde sua curiosidade, sua fé, seu projeto de trabalho e sua abertura para a alteridade o levaram. Caminhou com um olho nos indícios do que poderia ter sido o passado e outro no que poderia vir a ser o presente; um pé na igreja católica, com seus rituais e dogmas, e outro na ciência, com suas rotinas produtivas e verdades produzidas; um ouvido sintonizado com o burburinho e a polissemia da fala das ruas e outro atento aos discursos que insinuavam falar em nome da verdade e do real; uma mão ocupada em exercitar gestos e rituais milenares e outra dedicada à escrita que fabulava outros mundos possíveis. Para Giard (2011), a unidade de todas as atividades do corpo e da mente em conjunção conferia um estilo único e inimitável ao trabalho da inteligência de Certeau.

Michel de Certeau, conforme Giard (2011, p. 7), tinha uma maneira inimitável para atravessar as fronteiras entre os campos do saber: "Não se incomodava em esperar um salvo-conduto no posto fronteiriço, tampouco em solicitar a autorização dos guardiões de determinado feudo". Em seu processo de formação, mas também em seu trabalho, integrou diferentes disciplinas das ciências humanas e sociais: História, Filosofia, Teologia, Antropologia, Sociologia, Psicanálise, Semiótica, entre outras. Ele não hesitava em avançar por diferentes campos, inventando o melhor percurso de investigação para abordar seu objeto de reflexão. Ainda para o autor, tal atitude gerava uma força, um elã contagioso. Para Cravetto (2003), era uma espécie de obsessão pela relação imprevisível entre ruptura e luto que 
pontuava, no trabalho de Certeau, a representação da própria vida. Trata-se, segundo ela, de uma lesão inicial, geradora da atividade criadora, e também a superação da mesma lesão.

Para Certeau, conforme o concebemos, o Outro com o qual permanentemente se defrontava era, em potência, o mistério, a estranheza e a permanente surpresa, portanto, o imprevisível, no encontro com o qual poderia se estabelecer a crise do crível, ou seja, a quebra dos padrões habituais de referências, valores, pensamentos e ações. Um vazio em relação ao que era tido como certo, ao que era admitido e desejado. Com o sentimento de perda viria então o luto, e depois dele, a não identificação e a abertura para a alteridade radical e para as mudanças que esse deslocamento possibilita. Nas palavras do próprio Certeau (1970, p. 7),

Habitualmente, o estranho circula discretamente sob nossas ruas. Mas, é suficiente uma crise para que, de todos os lados, como que trazido por uma enchente, ele suba do sub-solo [sic], levantando as coberturas dos esgotos, invadindo os andares baixos e, em seguida, toda a cidade. Que o noturno apareça, brutalmente, à luz do dia, é coisa que, a cada vez, surpreende. Esta força a descoberto se insinua nas tensões da sociedade que ela ameaça. Frequentemente, ela as agrava; utiliza ainda os meios e os circuitos existentes, mas ao serviço de uma "inquietude" que vem de mais longe e que não se espera; ela quebra as fechaduras; ela faz transbordar as canalizações sociais; ela abre caminhos que deixarão, após sua passagem, quando o fluxo se retira, uma outra paisagem e uma ordem diferente.

Com uma atitude epistemológica em que articulava diferentes conhecimentos e modos de conhecer forjados em diferentes campos e contextos, Michel de Certeau elaborou, ao longo de sua trajetória, novos objetos de estudo e novos procedimentos 
metodológicos. Apesar da diversidade dos temas e dos espaçostempos estudados, sua obra desenvolveu-se em torno de domínios identificáveis: a escrita da história ou a operação historiográfica, a história das crenças, a mística e a espiritualidade, a psicanálise, a cultura em sua pluralidade/multiplicidade, as mídias e as tecnologias da informação e as práticas culturais cotidianas.

Tendo iniciado sua investigação histórica com trabalhos sobre a mística cristã medieval, escreveu ensaios sobre os acontecimentos de Maio de 1968 e sobre o declínio do cristianismo na contemporaneidade; investigou a epistemologia da história e, por tabela, das ciências sociais; analisou as transformações culturais produzidas pelas mídias, pelas migrações, pelas minorias nascentes e pela ascensão das massas às universidades; e desenvolveu metodologias e conceitos que potencializam a compreensão e valorização das artes de dizer e de fazer cotidianas.

Apesar da aparente dispersão entre interesses, métodos e domínios de campos do saber que poderiam caracterizar a sua obra à primeira vista, Maigret (2000) sugere que um projeto de análise da modernidade emanava de seus escritos. Segundo ele, esse projeto começou com o estudo do misticismo como uma manifestação de secularização e com o estudo da secularização como invenção de um espaço autônomo de práticas culturais. Nessa direção, uma nova teoria de crenças e práticas, e as ligações entre elas, completaria um projeto que buscava identificar as mudanças trazidas pela modernidade.

Os deslocamentos que experimentou com as tantas viagens (físicas ou intelectuais) que fez ao encontro do Outro, da alteridade, e as desnaturalizações em relação ao que era tido como habitual e já sabido com eles engendradas lhe possibilitaram investir em uma combinatória de procedimentos investigativos e analíticos. Isto resultou em uma perspectiva de abordagem da constituição e transformação do social inédita e alternativa em 
relação às abordagens tradicionais à época, entre elas o marxismo e o estruturalismo.

De acordo com Maigret (2000), ao apontar a potência transformadora e a insubmissão produzidas pelas práticas cotidianas realizadas por homens e mulheres comuns, Certeau refutou as ideias de alienação e de determinismo, instituindo, na nossa compreensão, a possibilidade de uma análise crítica e otimista (mas não ingênua) da ação social no contexto das relações desiguais de poder, a qual, para alguns estudiosos de seu trabalho, como Maigret (2000), Josgrilberg (2005) e Vidal (2005), inscreve-se no campo dos Estudos Culturais.

No entrecruzamento de métodos que praticou sem prestar vassalagem a nenhum deles (Giard, 1994, p. 10), o aporte da Psicanálise pode ter sido importante para a escuta dos sinais que vêm de um Outro que é inapreensível em sua estranheza, falta ou ausência. Conforme Assunção (2005, p. 37):

A Psicanálise, assim como a História, emprega mecanismos semelhantes na construção desse saber: ambas, buscam por meio dos vestígios, dos restos, dos indícios, dos traços, dos sinais... /fontes, um modo de preenchimento de um vazio sempre a ser preenchido... a presença destes não implica presença absoluta; ela é sempre uma presença da falta, de uma ausência... é preciso escutar cada uma delas e o sujeito do qual elas falam.

A escuta atenta e a abertura para o Outro, para a diferença, para a diversidade, para a alteridade, permeia toda a obra de Michel de Certeau, caracterizando a atitude ético-política que o moveu. Mas, quem é o outro? Ou melhor, quem são os outros para Certeau? Arriscamo-nos a afirmar que, para ele, o Outro é, primeiramente, Deus. "O Deus da minha fé não cessa de frustrar e guiar o desejo que busca compreendê-lo. Ele o frustra porque 
nada do que eu sei é Ele. Ele o guia porque eu não o esperava lá aonde ele vem... ele só é o Mesmo aparecendo como Outro" (Certeau, 2006, p. 5).

O reconhecimento do declínio da influência da Igreja diante das mudanças sociais de sua época, provocadas em grande parte pelas migrações e pelas tecnologias da comunicação, lhe colocou o desafio e a tarefa cristã de restabelecer a comunicação de forma aberta com os Outros. Nessa perspectiva, abrir-se ao estrangeiro seria atualizar a linguagem e os significados diante da presença do Outro (Josgrilberg, 2005).

O Outro, no entanto, assume diferentes configurações nos escritos de Certeau. O Outro é o que tem outros valores, crenças, hábitos, saberes. O Outro é aquele ou aquilo que emerge com as crises do crível e engendra credibilidades nascentes. O Outro é aquele ou aquilo que não se possui nem se controla. O Outro é o que escapa. É o imprevisível, o inesperado, o excluído, o imigrante, o marginalizado, o estrangeiro. O Outro é mistério e é surpresa. É a alteridade radical, a diferença para a qual nós precisamos nos abrir para criar.

Considerando a complexidade e a operacionalidade da abordagem, Cravetto (2003) assinalou que em períodos de crise e desordem social e política, quando temos dificuldades para esclarecer as mudanças que estão ocorrendo, torna-se tarefa urgente e necessária voltarmos ao projeto de Certeau, o qual, segundo ela, pode ser caracterizado pelo trabalho de reconhecimento constante do aqui e agora, o que pressupõe uma emancipação do pensamento, um processo que comporte uma interrogação inventiva de saberes e uma elaboração rigorosa de conhecimentos que não seja subserviente aos modelos ideológicos dominantes.

Michel de Certeau era, para Luce Giard (1994, p. 9) um desses espíritos "anticonformistas e perspicazes", "cuja irradia- 
ção intelectual segue caminhos estranhos à lógica das instituições, quer estas se achem ligadas à Universidade, à Igreja ou ao Estado". Estava sempre em movimento e nunca se identificava a um lugar. Ele era ainda adolescente quando a Segunda Grande Guerra eclodiu na Europa e atuou, por um breve período, em um grupo de resistência ao nazismo.

Estava em Paris em maio de 1968, quando se propôs a pensar as manifestações e as mudanças sociais que estavam em curso em meio ao clamor dos acontecimentos. Em suas andanças pelo mundo, conheceu a desigualdade social, o autoritarismo, a exploração econômica, a miscigenação, o preconceito, a exclusão e a pobreza; mas também foi capaz de enxergar, acima de tudo, o poder de resistência, de negociação, de hibridização e de invenção engendrados com as práticas culturais cotidianas.

Esteve no Brasil pela primeira vez em 1966, período da ditadura militar, sensibilizado com a situação política do país. O conhecimento sobre o Brasil, contudo, de acordo com Vidal (2005), antecedia às viagens e vinha de leituras, entre elas, trabalhos de Paulo Freire. Apoiado no educador brasileiro, Michel de Certeau, em um artigo que escreveu para a revista Pédagogie, concebeu a relação pedagógica como um diálogo entre gerações e a aula como um lugar onde se deve exercitar a liberdade.

Em A cultura no plural, tocado por maio de 1968, Certeau refletiu sobre as escolas, as universidades e as mudanças culturais, mas foi a obra $A$ invenção do cotidiano que obteve melhor recepção e que foi mais apropriada no Brasil, produzindo ressonâncias nas Ciências Humanas e Sociais.

Nessa perspectiva, defendemos que a contribuição de Certeau ao campo da Educação é inestimável e, além de sua atitude política e em pesquisa, se substancializa na crítica à epistemologia das Ciências Socais e Humanas e, principalmente, 
em sua empreitada teórica para construir uma epistemologia das práticas cotidianas, as quais estão, segundo ele, no cerne da constituição e transformação do social, do cultural, do político, do científico e do educativo, mobilizando procedimentos metodológicos e criando conceitos para apreendê-las e analisá-las. 